\title{
Possible Renal Repairing Mechanisms of Mesenchymal Stem Cells in Cyclosporine-Mediated Nephrotoxicity: Endothelial Viability and Hemodynamics
}

\author{
Elshahat Abo-Mosalam Toson', Hanaa Hamdy Ahmed², Hatem Abdel Moneim El-mezayen³, \\ Laila Ahmed Rashed ${ }^{4}$, Eslam Samy Elsherbiny ${ }^{1, *}$ \\ ${ }^{1}$ Chemistry Department, Faculty of Science, Damietta University, Damietta, Egypt \\ ${ }^{2}$ Hormones Department, National Research Center, Dokki, Giza, Egypt \\ ${ }^{3}$ Chemistry Department, Faculty of Science, Helwan University, Cairo, Egypt \\ ${ }^{4}$ Medical Biochemistry Department, Unit of Biochemistry and Molecular Biology, Faculty of Medicine, Cairo University, Cairo, Egypt \\ *Corresponding author. E-mail: eslamsamy1@yahoo.com
}

Received date: Oct 26, 2018; Revised date: Dec 11, 2018; Accepted date: Dec 28, 2018

\section{Abstract}

$\mathrm{B}$ ACKGROUND: Stem cell-based therapy may represent the first realistic option for tissue repairing and regeneration. Mesenchymal stem cells (MSCs) are proved to be involved in the regeneration of many tissues which are subjected to different types of injury. Cyclosporine (CsA) in spite of its use as immune suppressive drug during kidney transplantation, it was considered as important model of nephropathy specially, during long-term administration.

METHODS: Isolation and preparation of MSCs using Dulbecco's modified Eagle's medium (DMEM), in vitro differentiation through adipogenesis chondrogenesis and osteogenesis was confirmed by using Alizarin Red S stain, Oil Red O stain and Alcian Blue stain, respectively, characterization using flow cytometry technique to detect cluster of differentiation (CD)34, CD44 and CD105 surface markers and homing of MSCs using polymerase chain reaction (PCR) Sry gene assay, were executed. Serum levels of vascular endothelial growth factor (VEGF), endothelin-1 (ET-1) and endothelial nitric oxide synthase (eNOS) were quantified using enzyme-linked immunosorbent assay (ELISA) kits based on the principle of double-antibody sandwich technique. The structural organization of kidney tissue was examined using histological procedures.

RESULTS: Single intravenous dose of MSCs is capable to boost kidney repairment process as indicated by the significant decrease in serum ET-1 level paralleled by significant increase in VEGF and eNOS. Moreover, histological findings revealed the improvement of focal hemorrhage in between the degenerated tubules, congestion in the cortical blood vessels, vacuolization in the endothelial cells lining the glomerular tufts and focal perivascular inflammatory cells aggregation.

CONCLUSION: This study demonstrated the favorable influence of MSCs in repressing cyclosporine-induced nephropathy in rats. This could be achieved through angiogenic and anti-arteriolopathic mechanisms.

KEYWORDS: angiogenesis, cyclosporine, endothelin-1, MSCs, nephropathy

Indones Biomed J. 2019; 11(2): 145-51

\section{Introduction}

Induction of renal arteriolopathy by cyclosporine (CsA) nephrotoxicity may be augmented by the action of vasoactive molecules mainly vasoconstrictors. Nitric oxide (NO) plays an important role in renal physiology and pathophysiology. (1) NO was first found in 1987 to be typical with endothelial derived relaxing factor (EDRF) (2), and this was followed by a quick package of information identifying the significance of NO not only in vascular system and hemodynamics but also in nervous and immune defense systems (3). 
Endothelin-1 (ET-1) is the most powerful mammalian vasoconstrictor. In 1990, the document came out to link ET-1 with acute CsA nephrotoxicity. CsA has been found to stimulate ET-1 production in cultured renal epithelial cells and the renal ET receptors have been shown to be amplified in rats with CsA-induced nephrotoxicity.(4) Vascular endothelial growth factor (VEGF) is considered as signal protein of the formation of new blood vessels (5), it has main role on acute and chronic renal diseases $(6,7)$. In late stages of renal disease, down regulation of VEGF expression and increasing of capillaries injury were observed in CsAmediated nephrotoxicity.

Angiotensin II is a well-known growth factor stimulating the activity of fibroblast, leading to deposition of extracellular matrix, and the scarring of tissue. Administration of angiotensin II in rats for a long period induces tubulointerstitial damage. This damage is also observed after chronic CsA administration.(8) The blockade of renin angiotensin system (RAS) in chronic CsA nephropathy by angiotensin converting enzyme inhibitor (ACEI) decreases blood pressure, potentiates vasodilation of afferent arteriole, and ameliorates interstitial fibrosis. (9) Mesenchymal stem cells (MSCs) are proved to be involved in the regeneration of many tissues subjected to different types of injury.(10) Since, bone marrow derived mesenchymal stem cells (BM-MSCs) and adipose tissue derived mesenchymal stem cells (AD-MSCs) have been evaluated in a chronic renal damage model with promising results. AD-MSCs and BM-MSCs sources of MSCs were used to treat the nephrotoxic effects of CsA in this study.

Herein, the focus of our study is to explore the mechanisms behind the therapeutic efficacy of BM-MSCs and AD-MSCs in mitigating nephrotoxicity induced by CsA in rats. In addition, the study was extended to elucidate the role of stem cell versus angiotensin converting enzyme inhibitor in kidney repair. Moreover, introducing awareness for the nephrologists for renal dysfunction due to CsA administration.

\section{Methods}

Isolation and preparation of MSCs were established according to Alhadlaq and Mao (11) and Tomiyama, et al., (12) using Dulbecco's modified Eagle's medium (DMEM) (GIBCO/BRL, New York, USA), supplemented with 10\% foetal bovine serum (GIBCO/BRL). In addition, to confirm the mesenchymal nature of the isolated cells, in vitro differentiation of bone marrow and adipose derived cells including adipogenesis assay (13), chondrogenesis assay (14) and osteogenesis assay (15) was done. Moreover, flow cytometry (Beckman Coulter Elite XL, California, USA) was used to detect cluster of differentiation (CD)34, CD44 and CD105 surface markers in order to confirm whether the isolated BM-MSCs and AD-MSCs maintain their phenotype after expansion in culture.(16) Moreover, isolated MSCs from normal female rats were inoculated in male rats to confirm their renal homing using polymerase chain reaction (PCR) Sry gene assay.(17)

\section{Animals}

Adult female Wistar rats weighed 130-150 gram, were used in this study. Rats were housed in a controlled area where temperature $\left(25 \pm 1^{\circ} \mathrm{C}\right)$ and humidity $(55 \%)$ were set with free access of food and water. Guidelines of the Ethical Committee of the National Research Centre, Egypt (IRB approval number 14 036) were followed, which conform to the recommendations of the National Institutes of Health guide for the care and use of Laboratory animals (NIH Publications No. 8023, revised 1978).

Nephropathy was induced in rats by a daily subcutaneous injection of cyclosporine (Novartis Pharma, Basel, Switzerland) at the dose of $15 \mathrm{mg} / \mathrm{kg}$ dissolved in olive oil for 28 days.(18) Dose of angiotensin converting enzyme inhibitors (ACEI); $40 \mathrm{mg} / \mathrm{L}$ Lisinopril (Zestril, AstraZeneca, Cambridge, UK) in drinking water, was chosen based on of previously published study.(19)

\section{Experimental Set-up}

This study included 64 adult female rats, divided into five groups, which are control group ( 8 rats), healthy rats received $1 \mathrm{~mL}$ of olive oil subcutaneously for 28 days; CsA group ( 8 rats), healthy rats received $15 \mathrm{mg} / \mathrm{kg}$ of cyclosporin A subcutaneously for 28 days; BM-MSCstreated group (16 rats), nephropathic rats infused with a single dose of undifferentiated BM-MSCs $\left(3 \times 10^{6}\right.$ cells $)$ intravenously (20); AD-MSCs-treated group (16 rats), nephropathic rats infused with a single dose of AD-MSCs $\left(3 \times 10^{6}\right.$ cells) intravenously (21); ACEI-treated group (16 rats), nephropathic rats received Lisinopril $(40 \mathrm{mg} / \mathrm{L})$ in drinking water for one month (8 rats) and two months (8 rats). After deeply anaesthetized using diethyl ether, the rats in the control group as well as in the CsA group were sacrificed after treatment. While, all treated groups divided into two subgroups equally and were sacrificed after one and two months post treatment. 


\section{Biochemical Analyses}

Serum creatinine and urea were estimated by auto analyzer A15 (Biosystem, Barcelona, Spain). Serum VEGF, ET-1 and endothelial nitric oxide synthase (eNOS) levels were determined according to the manufacturer's instructions by using enzyme-linked immunosorbent assay (ELISA) kits based on the principle of double-antibody sandwich technique, the optical density (OD) was measured under $450 \mathrm{~nm}$ wavelength within $10 \mathrm{~min}$ after adding the stop solution. The standard curve linear regression equation was calculated, and then OD values of the samples were applied on the regression equation to calculate the corresponding concentration of samples. Kits were purchased from Glory Science Co. (Del Rio, Texas, USA).

\section{Histopathological Investigation}

After fixation of kidney samples in $10 \%$ formalin saline for twenty-four hours, paraffin wax tissue blocks were prepared for sectioning at 4 microns by microtome. The obtained tissue sections were collected on glass slides, deparaffinized and stained by hematoxylin and eosin (H\&E) stains for histopathological examination.(22)

\section{Statistical Analysis}

All results were expressed as Mean \pm standard deviation (SD). Data were analyzed by one way analysis of variance (ANOVA) using the Statistical Package for the Social Sciences (SPSS) program, version 17 followed by least significant difference (LSD) to compare significance between groups. Difference was considered significant when $p$-value $<0.05$.

\section{Results}

Our previous data have shown that, the adherent cells from bone marrow and adipose tissue generated many colonies and displayed a heterogeneous morphology with elongated spindle like shape. Moreover, differentiation of BM-MSCs and AD-MSCs through adipogenesis chondrogenesis and osteogenesis was confirmed by using Alizarin Red S stain, Oil Red O stain and Alcian Blue stain, respectively. $(23,24)$ Flow cytometry findings showed that BM-MSCs were positive for CD44 (77.1 \pm 18.1$)$ and CD105 (78.7 \pm 16.3$)$ and negative for CD34 (1.62 \pm 0.43$)$. Also, AD-MSCs characterization using flow cytometry showed CD44 positive $(81.2 \pm 19.6)$ and $\mathrm{CD} 105$ positive $(74.3 \pm 16.9)$, but CD34 negative (3.05 \pm 0.71$)$. Where, number of samples equal three from each type of MSCs.(17)
Also, our previous study revealed that the treatment with BM-MSCs, AD-MSCs and ACEI after one and two months evoked significant $(p<0.05)$ decline in serum creatinine and urea levels paralleled by significant $(p<0.05)$ elevation in glomerular filtration rate (GFR) value in comparison with CsA group.(17)

\section{Biochemical Markers}

Table 1 displayed the levels of serum ET-1, VEGF and eNOS in the different studied groups. CsA group showed significant $(p<0.05)$ rise of serum ET-1 along with significant $(p<0.05)$ drop of serum VEGF and eNOS levels compare to the control group. However, BM-MSCs, AD-MSCs and ACEI-treated groups showed significant $(p<0.05)$ changes in serum ET-1, VEGF and eNOS levels as compared to CsA group.

By comparing the data of BM-MSCs, AD-MSCs and ACEI-treated groups after 2 months with those treated after 1 month, it show that there was significant $(p<0.05)$ increase in serum eNOS level after 2 months of treatment. Meanwhile, there was significant $(p<0.05)$ decline in serum eNOS leve 1 of AD-MSCs treated group after 1 month versus that treated with BM-MSCs after 1 month. Treatment with ACEI for 2 months led to significant $(p<0.05)$ depletion in serum VEGF level versus the groups of rats treated either with ACEI for 1 month or BM-MSCs for 2 months.

\section{Histopathological Findings}

Control group showed normal histological organization of the glomeruli and tubules at the cortex (Figure 1A). CsA group revealed focal hemorrhage in between the degenerated tubules at the cortex associated with congestion in the cortical blood vessels and perivascular inflammatory cells infiltration (Figure 1B). BM-MSCs-treated group (after one month) revealed focal hemorrhage in between the degenerated tubules at the corticomedullary portion associated with congestion in the cortical blood vessels, swelling and vacuolization in the endothelial cells lining the glomerular tufts (Figure 1C). After 2 months of treatment with BM-MSCs, congestion in the cortical blood vessels was observed (Figure 1D). AD-MSCs-treated group (after one month) revealed mild congestion in the cortical portion (Figure 1E). There was no histopathological alteration seen after two months of treatment with AD-MSCs (Figure 1F). Treatment with ACEI led to focal hemorrhage and hemolysis between the degenerated tubules in corticomedullary portion after one month (Figure 1G) and mild congestion in the cortical blood vessels associated with focal perivascular inflammatory cells aggregation after 2 months (Figure 1H). 
Table 1. Serum levels of ET-1, VEGF and eNOS in the control group, CsA group and the treated groups with BM-MSCs, ADMSCs and ACEI after one and two months.

\begin{tabular}{|c|c|c|c|c|c|c|c|c|}
\hline \multirow{2}{*}{ Parameters } & \multirow{2}{*}{ Control group } & \multirow{2}{*}{ Cs A group } & \multicolumn{2}{|c|}{ BM-MSC- treated group } & \multicolumn{2}{|c|}{ AD-MSC- treated group } & \multicolumn{2}{|c|}{ ACEI- treated group } \\
\hline & & & $1^{\text {st }}$ Month & $2^{\text {nd }}$ Month & $1^{\text {st }}$ Month & $2^{\text {nd }}$ Month & $\mathbf{1}^{\text {st }}$ Month & $2^{\text {nd }}$ Month \\
\hline Endothelin-1 (ng/L) & $10.3 \pm 1.0$ & $16.02 \pm 2.1^{\mathrm{a}}$ & $13.53 \pm 1.03^{b}$ & $13.2 \pm 0.55^{\mathrm{b}}$ & $13.1 \pm 1.8^{\mathrm{b}}$ & $11.5 \pm 0.85^{\mathrm{b}}$ & $14.6 \pm 2.4$ & $13.6 \pm 3.3^{b}$ \\
\hline VEGF (ng/L) & $516 \pm 18.3$ & $239.7 \pm 11.7^{\mathrm{a}}$ & $305.5 \pm 9.99^{\mathrm{b}}$ & $313.3 \pm 16.6^{\mathrm{b}}$ & $298.6 \pm 12^{\mathrm{b}}$ & $316.6 \pm 6.8^{\mathrm{b}}$ & $309.6 \pm 9.5^{\mathrm{b}}$ & $293 \pm 19.1^{\text {ef }}$ \\
\hline eNOS (U/mL) & $5.9 \pm 0.56$ & $3.2 \pm 0.52^{\mathrm{a}}$ & $4.5 \pm 0.41^{\mathrm{b}}$ & $5.2 \pm 0.36^{\mathrm{bc}}$ & $3.9 \pm 0.22^{\mathrm{bc}}$ & $5.1 \pm 0.23^{\mathrm{bd}}$ & $4.3 \pm 0.35^{\mathrm{b}}$ & $4.8 \pm 0.3^{\text {be }}$ \\
\hline
\end{tabular}

a: significant change at $p<0.05$ in comparison with the control group; $\mathrm{b}$ : significant change at $p<0.05$ in comparison with the CsA group; $\mathrm{c}$ : significant change at $p<0.05$ in comparison with BM-MSCs-treated group after one month; d: significant change at $p<0.05$ in comparison with AD-MSCs-treated group after one month; e: significant change at $p<0.05$ in comparison with ACEI-treated group after one month; f: significant change at $p<0.05$ in comparison with BM-MSCs-treated group after two months.

\section{Discussion}

The positive effects of MSC in animal models of CKD were mentioned lastly, as indicated by the depletion of plasma creatinine levels (25), improvement of proteinuria (26), renal fibrosis (27), glomerulosclerosis (28), and renal filtration (29). Unfortunately, the exact mechanisms behind these reparative processes are presently unknown.

The long-term administration of CsA as immunosupressor agent for patients with renal and heart transplantation promote endothelial cell damage through high level of Von Willebrand factor, pselectin, thrombin complexes (30), and suppress basal and stimulated NO generation resulted in severe vascular disease.(31) CsA could also induce imbalance in the rate of vasodilator to vasoconstrictor in favor of vasoconstriction leading to lowgrade ischemic injury, which is likely associated with CsA nephrotoxicity.(32) Therefore, the decrease in GFR after CsA injection suggests the involvement of vasoconstriction in the mechanism of its nephrotoxicity.

The simultaneous significant elevation in serum creatinine and urea levels in CsA-group versus the control group confirms the later suggestion. CsA has been found to increase ET-1 production from renal epithelial cell culture and the renal ET receptors showed overexpression in rats with nephrotoxicity induced by CsA.(4) The excess production of thromboxane due to CsA is linked with the activated infiltrating platelets and macrophage in kidney tissue, amplification of kidney lipid peroxidation, and generation of ROS with consequent endothelial injury.(33) This supports the study by another study which proved that CsA-induced chronic ischemia is associated with ROS and lipid peroxidation.(34) In addition, the significant attenuation of CsA nephropathy after antioxidants supplementation confirms this idea.(35) The restricted expression of VEGF in glomerular and some tubular cells of adult kidneys confirms its implication in maintaining permeability and integrity of the glomerulus's capillaries. The results of this study showed that serum level of VEGF is significantly reduced in CsA group relative to the control group. This reduction emphasizes the involvement of VEGF in CsAmediated nephrotoxicity. Surprisingly, the mean level of such marker is significantly elevated in serum of rats after treatment with both AD-MSCs and BM-MSCs in a time dependent manner. This elevation may suggest an induction of a vascular protection-related pathway by the inoculated MSC in this study. The essentialities of VEGF in endothelial and vascular system development and in glomerulogenesis confirm our later suggestion.

More evidence in the implication of MSCs in the promotion of angiogenesis is by acting as pericyte-like cells to support the new vasculature and/or secreting molecules strongly associated with the angiogenetic process including VEGF, insulin-like growth factor 1 (IGF-1), hepatocyte growth factor (HGF), placental growth factor (PIGF), monocyte chemoattractant protein-1 (MCP-1), plateletderived growth factor (PDGF) and fibroblast growth factor 2 (FGF-2). $(36,37,38)$ A somewhat similar kidneys repair mechanism may be involved in MSCs-treated rats, in our study. This mechanism agrees with the protective role of VEGF against glomerular injury.(29,39) Moreover, the results of Miyamoto, et al., showed that VEGF expression is inversely correlated with the development of glomerulosclerosis in progressive renal diseases necessitate the implication of the latter mechanism.(40)

CsA-induced acute renal injury, is believed to be associated with abnormal expression of nitric oxide synthase (NOS).(41) Previous studies cited that the changes in eNOS and inducible nitric oxide synthase (iNOS) expression in 

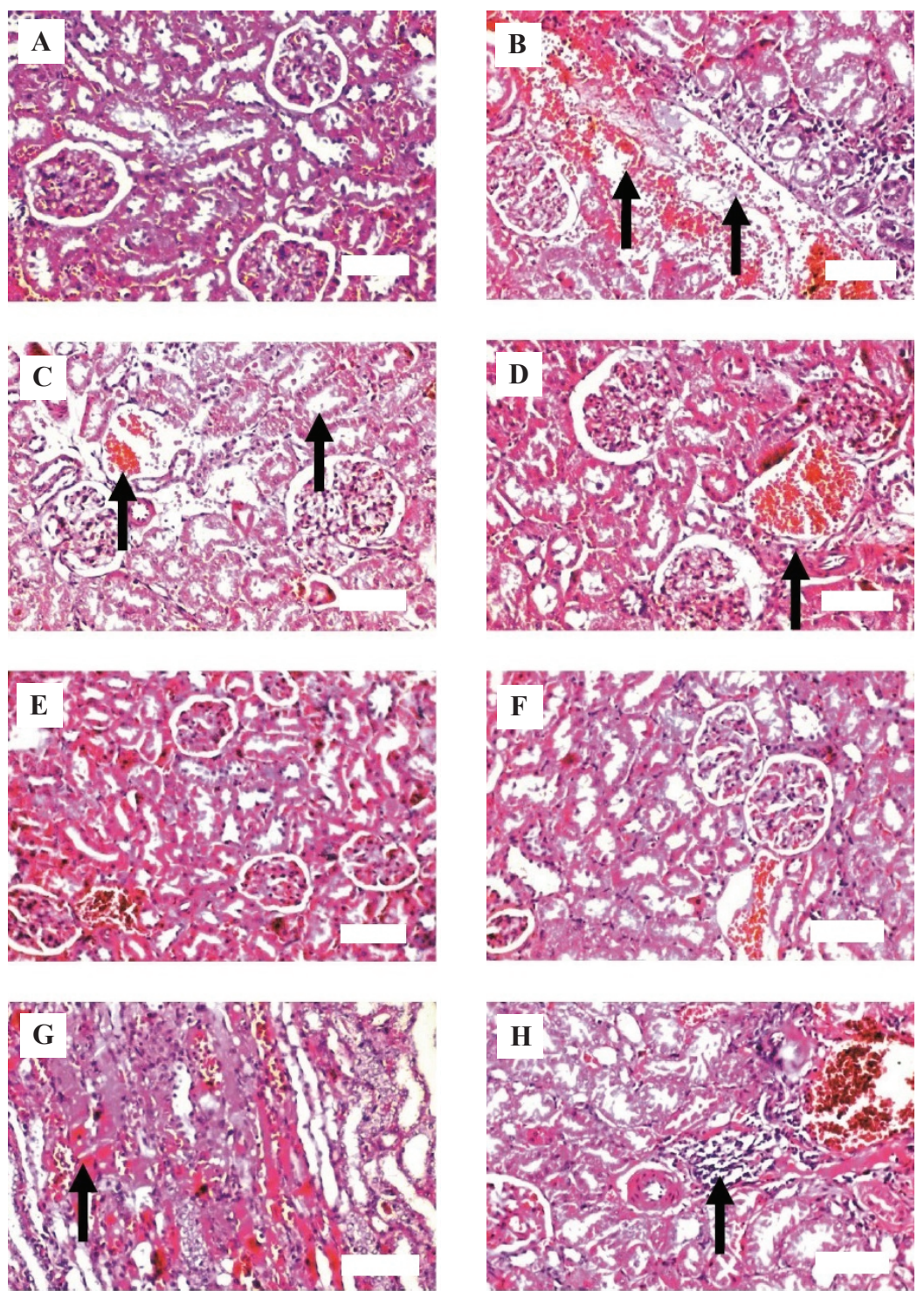

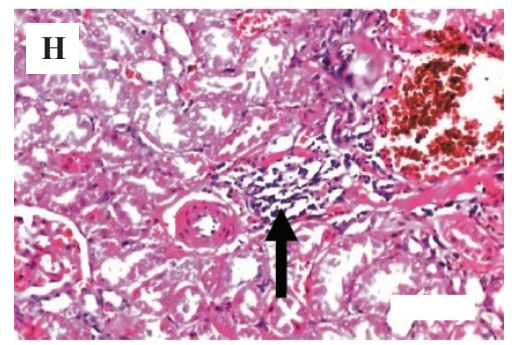

Figure 1. Histopathological findings of study subjects. A: no histopathological change and the normal histological organization of the glomeruli and tubules at the cortex are seen in the photomicrograph of kidney tissue section of rat in the control group; $\mathrm{B}$ : focal hemorrhage is detected in between the degenerated tubules at the cortex associated with congestion in the cortical blood vessels and perivascular inflammatory cells infiltration are noticed in photomicrograph of kidney tissue section of rat in CsA group; $\mathrm{C}$ : focal hemorrhage in between the degenerated tubules at the corticomedullary portion associated with congestion in the cortical blood vessels and swelling as well as vacuolization in the endothelial cells lining the glomerular tufts are seen in photomicrograph of kidney tissue section of rat in the BM-MSCs-treated group for one month; D: congestion is noticed in the cortical blood vessels in photomicrograph of kidney tissue section of rat in BM-MSCs-treated group for two months; E: mild congestion in the cortical portion is detected in photomicrograph of kidney tissue section of rat in AD-MSCs-treated group for one month; F: no histopathological alteration is seen in photomicrograph of kidney tissue section of rat in AD-MSCs-treated group for two months; G: The corticomedullary portion showing focal hemorrhage and hemolysis between the degenerated tubules in photomicrograph of kidney tissue section of rat in ACEI-treated group for one month; $\mathrm{H}$ : mild congestion in the cortical blood vessels associated with focal perivascular inflammatory cells aggregation are detected in photomicrograph of kidney tissue section of rat in ACEI group for two months. White bar: $100 \mu \mathrm{m}$. the diseased kidneys cause a sustained afferent arteriolar vasoconstriction.(41-43)

VEGF has been found to induce endothelial NO formation and this mechanism has a favorable impact in maintaining endothelial cell viability (44), inhibition of vascular inflammation and suppression of the vascular smooth muscle cell activation resulting in preservation of vascular integrity.(5) Meanwhile in this study, not only the serum levels of VEGF but also NOS levels are significantly increased in-group injected with BM-MSCs or AD-MSCs, compared with those in CsA group. These increments might be one of the mechanisms by which these cells can participate to ameliorate CsA-induced nephrotoxicity.

Noteworthy, the serum level of NOS in rats treated with MSCs is negatively correlated with transforming growth factor (TGF)- $\beta$ level in the same animal groups (data not shown). NOS inhibition in rats via L-arginine analogue leads to increased afferent arterioles construction, which is associated with local activation of RAS and overexpression of TGF- $\beta$ in the kidneys.(45) In addition, A progressive nephropathy induced by $\mathrm{CsA}$ can be modulated by NO stimulation with consequent downregulation of TGF- $\beta$ expression.(46) Since TGF- $\beta$ is a key player in the development of renal fibrosis by direct stimulation of extracellular matrix (ECM) components and inhibition of collagenase production, will ultimately resulting in renal scarring (47), in which one can state that the stimulation of NOS to the suggested mechanisms of kidney repairs by MSCs in the present study.

ET-1 can also disrupt renal architecture due to its impact on ECM accumulation and tubulointerstitial fibrosis. However, both vasoconstriction and afferent 
arteriolopathy have been shown to be normalized paralleled by improvement of the histological feature of kidney in the groups treated with MSCs particularly AD-MSCs. The normalization of both vasoconstriction and afferent arteriolopathy detected in ACEI, BM-MSCs and AD-MSCstreated groups confirm this suggested mechanism. Also, the disruption of renal architecture and the tubulointerstitial inflammation observed in CsA model and the disappearance of most of these abnormalities after treatment with MSCs add more light to the previous proposed mechanisms.

Another important mechanism on the line of impairing nephrotoxicity induced by CsA involves activation of RAS via hemodynamic pathway. This is mediated by inhibition of angiotensin II which is a causative factor of endothelial cell apoptosis in vitro.(48) This is because of the treatment of rats with ACEI, Lisinopril causes an elevation in the level of eNOS but decreases ET-1 compared with CsAchallenged rats, with a simultaneous improvement in kidney architecture. The vasoconstricting activity which is partially related to the activation of RAS, ET-1 and imbalance in prostaglandins and thromboxane (49), confirms the possibility of a mechanism based on RAS inhibition to be involved in kidney repair after treatment with Lisinopril.

\section{Conclusion}

this study demonstrated that cell therapy elicited angiogenesis and anti-arteriolopathic effects in a rat model of nephropathy induced by CsA. The increment of eNOS and VEGF may be one of the mechanisms underlying the renoprotective properties of mesenchymal stem cell. Moreover, our findings shed more light on the potential rationale for the clinical application of stem cell-based therapy in kidney diseases.

\section{References}

1. Busauschina A, Schnuelle P, van der Woude FJ. Cyclosporine Nephrotoxicity. Transplant Proc. 2004; 2: 229S-33S.

2. Ignarro LJ, Buga GM, Wood KS, Byrns RE, Chaudhuri G Endothelium derived relaxing factor produced and released from artery and vein is nitric oxide. Proc Natl Acad Sci USA. 1987; 84: 9265-9.

3. Sharma SP. Nitric oxide and the kidney. Indian J Nephrol. 2004; 14: 77-84.

4. Perico N, Dadan J, Remuzzi G. Endothelin mediates the renal vasoconstriction induced by cyclosporine in the rat. J Am Soc Nephrol. 1990; 1: 76-83

5. Kanesaki Y, Suzuki D, Uehara G, Toyoda M, Katoh T, Sakai H, et $a l$. Vascular endothelial growth factor gene expression is correlated with glomerular neovascularization in human diabetic nephropathy. Am J Kidney Dis. 2005; 45: 288-94.

6. Kang D, Nakagawa T, Feng L, Johnson RJ. Nitric oxide modulates vascular disease in the remnant kidney model. Am J Pathol. 2002; 161: 239-48.

7. Masuda Y, Shimizu A, Mori T, Ishiwata T, Kitamura H, Ohashi R, et al. Vascular endothelial growth factor enhances glomerular capillary repair and accelerates resolution of experimentally induced glomerulonephritis. Am J Pathol. 2001; 159: 599-608.

8. Ruiz-Ortega M, Egido J. Angiotensin II modulates cell growthrelated events and synthesis of matrix proteins in renalinterstitial fibroblasts. Kidney Int. 1997; 52: 1497-510.

9. Lassila M, Finckenberg P, Pere AK, Krogerus L, Ahonen J, Vapaatalo $\mathrm{H}$, et al. Comparison of enalapril and valsartan in cyclosporine A-induced hypertension and nephrotoxicity in spontaneously hypertensive rats on high-sodium diet. Br J Pharmacol. 2000; 130: 1339-47.

10. De Girolamo L, Lucarelli E, Alessandri G, Avanzini MA, Bernardo ME, Biagi E, et al. Mesenchymal stem/stromal cells: A new"cells as drugs" paradigm. Efficacy and critical aspects in cell therapy. Curr Pharm. 2013; 19: 2459-73

11. Alhadlaq A, Mao JJ. Mesenchymal stem cells: isolation and therapeutics. Stem Cells Dev. 2004;13: 436-48.

12. Tomiyama K, Murase N, Stolz DB, Toyokawa H, O'Donnell DR, Smith DM, et al. Characterization of transplanted GFP+ bone marrow cells into adipose tissue stem cells. 2008; 26: 330-8.

13. Rombouts WJ, Ploemacher RE. Primary murine MSC show highly efficient homing to the bone marrow but lose homing ability following culture. Leukemia. 2003; 17: 160-70.

14. Peister A, Mellad JA, Larson BL, Hall BM, Gibson LF, Prockop DJ. Adult stem cells from bone marrow (MSCs) isolated from different strains of inbred mice vary in surface epitopes rates of proliferation and differentiation potential. Blood. 2004; 103:1662-8.

15. Phinney DG, Kopen G, Isaacson RL, Prockop DJ. Plastic adherent stromal cells from the bone marrow of commonly used strains of inbred mice: variations in yield, growth and differentiation. J Cell Biochem. 1999; 72: 570-85.

16. Woodbury D, Schwarz EJ, Prockop DJ, Black IB. Adult rat and human bone marrow stromal cells differentiate into neurons. J Neurosci Res. 2000; 61: 364-70.

17. Ahmed HH, Toson EA, El-mezayen HA, Rashed LA, Elsherbiny ES. Role of mesenchymal stem cells versus angiotensin converting enzyme inhibitor in kidney repair. Nephrology. 2017; 22: 531-40.

18. Li C, Yang CW, Park JH, Lim SW, Sun BK, Jung JY, et al. Pravastatin treatment attenuates interstitial inflammation and fibrosis in a rat model of chronic cyclosporine-induced nephropathy. Am J Physiol Renal Physiol. 2004; 1286: F46-57.

19. Zoja C, Donadelli R, Corna D, Testa D, Facchinetti D, Maffi R, et $a l$. The renoprotective properties of angiotensin-converting enzyme inhibitors in a chronic model of membranous nephropathy are solely due to the inhibition of angiotensin II: Evidence based on comparative studies with a receptor antagonist. Am J Kidney Dis. 1997; 29: 254-64.

20. Zhao DC, Lei JX, Chen R, Yu WH, Zhang XM, Li SN, et al. Bone marrow-derived mesenchymal stem cells protect against experimental liver fibrosis in rats. World J Gastroentrol. 2005; 214: 3431-40.

21. El Ansary M, Saadi G, Abd El-Hamid SM. Mesenchymal stem cells are a rescue approach for recovery of deteriorating kidney function. Nephrology. 2012; 17: 650-7.

22. Banchroft JD, Stevens A, Turner DR. Theory and Practice of Histological Techniques. 4rd ed. New York: Churchil Livingstone; 1996. 
23. Ahmed HH, Mahdy EE, Shousha WG, Rashed LA, Abdo SM. Potential role of bone marrow derived mesenchymal stem cells with or without injectable calcium phosphate composite in management of osteoporosis in rat model. Int J Pharm Pharm Sci. 2013; 5: 494504.

24. Ahmed HH, Mahdy EE, Shousha WG, Rashed LA, Abdo SM. Influence of adipose tissue derived mesenchymal stem cells in combination with injectable bone substitute on osteoclastogenesis in osteoporotic rats. J Appl Pharm Sci. 2013; 3: 46-56.

25. Song JH, Humes HD. Renal cell therapy and beyond. Semin Dial. 2009; 22: 603-9.

26. Cavaglieri RC, Martini D, Sogayar MC, Noronha IL. Mesenchymal stem cells delivered at the sub capsule of the kidney ameliorate renal disease in the rat remnant kidney model. Transplant Proc. 2009; 41: 947-51.

27. Asanuma H, Vanderbrink BA, Campbell MT, Hile KL, Zhang H, Meldrum DR, et al. Arterially delivered mesenchymal stem cells prevent obstruction-induced renal fibrosis. J Surg Res. 2011; 168: 51-9.

28. Lee SR, Lee SH, Moon JY, Park JY, Lee D, Lim SJ, et al. Repeated administration of bone marrow-derived mesenchymal stem cells improved the protective effects on a remnant kidney model. Ren Fail. 2010; 32: 840-8.

29. Kelley R, Werdin ES, Bruce AT, Choudhury S, Wallace SM, Ilagan RM, et al. Tubular cell-enriched subpopulation of primary renal cells improves survival and augments kidney function in rodent model of chronic kidney disease. Am J Physiol Renal Physiol. 2010; 299: F1026-39.

30. Malyszko J, Malyszko JS, Pawlak K, Mysliwiec M. The coagulolytic system and endothelial function in cyclosporine-treated kidney allograft recipients. Transplantation. 1996; 62: 828-30.

31. Morris ST, McMurray JJ, Rodger RS, Farmer R, Jardine AG. Endothelial dysfunction in renal transplant recipients maintained on cyclosporine. Kidney Int. 2000; 57: 1100-6.

32. Olyaei AJ, De Mattos AM, Bennett WM. Nephrotoxicity of immunosuppressive drugs: new insight and preventive strategies. Curr Opin Crit Care. 2001; 7: 384-9.

33. Smith SR, Creech EA, Schaffer AV, Martin LL, Rakhit A, Douglas FL, et al. Effects of thromboxane synthase inhibition with CGS 13080 in human cyclosporine nephrotoxicity. Kidney Int. 1992; 41: 199-255.

34. Padi SS, Chopra K. Salvage of cyclosporine A-induced oxidative stress and renal dysfunction by carvedilol. Nephron. 2002; 92: 68592.

35. Jenkins JK, Huang H, Ndebele K, Salahudeen AK. Vitamin E inhibits renal mRNA expression of COX II, HO I, TGF beta, and osteopontin in the rat model of cyclosporine nephrotoxicity. Transplantation. 2001; 71: 331-4.

36. Au P, Tam J, Fukumura D, Jain RK. Bone marrow derived mesenchymal stem cells facilitate engineering of long-lasting functional vasculature. Blood. 2008; 111: 4551-8.

37. Sanz L, Santos-Valle P, Alonso-Camino V, Salas C, Serrano A, Luís Vicario $\mathrm{J}$, et al. Long-term in vivo imaging of human angiogenesis: critical role of bone marrow derived mesenchymal stem cells for the generation of durable blood vessels. Microvasc Res. 2008; 75: 308-14.

38. Meirelles LD, Fontes AM, Covas DT, Caplan AI. Mechanisms involved in the therapeutic properties of mesenchymal stem cells. Cytokine Growth Factor Rev. 2009; 20: 419-27.

39. Villanueva S, Cespedes C, Vio CP. Ischemic acute renal failure induces the expression of a wide range of nephrogenic proteins. Am J Physiol Regul Integr Comp Physiol. 2006; 290: R861-70.

40. Miyamoto K, Kitamoto Y, Tokunaga H, Takeya M, Ezaki T, Imamura $\mathrm{T}$, et al. Protective effect of vascular endothelial growth factor/ vascular permeability factor 165 and 121 on glomerular endothelial cell injury in the rat. Lab Invest. 2004; 84: 1126-36.

41. Bobadilla NA, Gamba G, Tapia E, García-Torres R, Bolio A, LópezZetina $\mathrm{P}$, et al. Role of $\mathrm{NO}$ in cyclosporine nephrotoxicity: Effects of chronic NO inhibition and NO synthases gene expression. Am J Physiol. 1998; 274: F791-8.

42. Zhong Z, Arteel GE, Connor HD, Yin M, Frankenberg MV, Stachlewitz RF, et al. Cyclosporin a increases hypoxia and free radical production in rat kidneys: Prevention by dietary glycine. Am J Physiol. 1998; 275: F595-604.

43. Amore A, Emancipator SN, Cirina P, Conti G, Ricotti E, Bagheri $\mathrm{N}$, et al. Nitric oxide mediates cyclosporine-induced apoptosis in cultured renal cells. Kidney Int. 2000; 57: 1549-59.

44. Ziche M, Morbidelli L, Choudhuri R, Zhang HT, Donnini S, Granger HJ, et al. Nitric oxide synthase lies downstream from vascular endothelial growth factor induced but not basic fibroblast growth factor induced angiogenesis. J Clin Invest. 1997; 99: 2625-34.

45. Kashiwagi M, Shinozaki M, Hirakata H, Tamaki K, Hirano T, Tokumoto $\mathrm{M}$, et al. Locally activated renin-angiotensin system associated with TGF- $\beta 1$ as a major factor for renal injury induced by chronic inhibition of nitric oxide synthase in rats. J Am Soc Nephrol. 2000; 11: 616-24.

46. Shihab FS, Yi H, Bennett WM, Andoh TF. Effect of nitric oxide modulation on TGF- $\beta 1$ and matrix proteins in chronic cyclosporine nephrotoxicity. Kidney Int. 2000; 58: 1174-85.

47. Islam M, Burke JF Jr, McGowan TA, Zhu Y, Dunn SR, McCue P, et al. Effect of anti-transforming growth factor- $\beta$ antibodies in cyclosporine-induced renal dysfunction. Kidney Int. 2001; 59: 498506.

48. DimmelerS, Rippmann V, Weiland U, Haendeler J, Zeiher AM. Angiotensin II induces apoptosis of human endothelial cells. Protective effect of nitric oxide. Circ Res. 1997; 81: 970-6.

49. Dell K, Bohler T, Gaedeke J, Budde K, Neumayer HH, Waiser J. Impact of PGE1 on cyclosporine A induced up-regulation of TGFbeta1, its receptors, and related matrix production in cultured mesangial cells. Cytokine. 2003; 22: 189-93. 